\title{
Coronavirus Disease (COVID) 2019 in Children - a Short Review
}

\section{IJCRR}

Section: Healthcare

Sci. Journal Impact

Factor: 6.1 (2018)

ICV: 90.90 (2018)

(c) (7) (3)

Copyright@IJCRR

\section{Sham Balkisanji Lohiya, Sachin Damke, Richa Chaudhary}

'Associate Professor, Department of Pediatrics, J.N.M.C. Sawangi (D.M.I.M.S.), Sawangi, Wardha, Maharashtra, India; ${ }^{2}$ Professor and HOD, Department of Paediatrics, J.N.M.C. Sawangi, Wardha, Maharashtra, India; ${ }^{3}$ Associate Professor, Department of Paediatrics, J.N.M.C. Sawangi, Wardha, Maharashtra, India.

\section{ABSTRACT}

Since December 2019, severe acute respiratory syndrome coronavirus 2 (SARS-CoV-2) has caused a series of Cases of severe pneumonia worldwide. It originated in Wuhan in Hubei province, China. SARS-CoV-2 causes infection by ACE receptors, similar to SARS. It causes potential damage to vital organs, mainly the lungs. COVID- 19 mainly affects respiratory tract with symptoms ranging from upper respiratory tract infection like symptoms to full-blown ARDS. Although the pediatric age group is shown to be less susceptible to severe infection, they can very well act as an intermediate in the transmitter of the virus. Treatment is symptomatic for mild diseases, but severe disease and ARDS require ICU management and specific treatment.

Key Words: COVID 19, Neonate, Pediatrics, Suspetible, Treatment

\section{INTRODUCTION}

Coronavirus belongs to the family Coronaviridae, order Nidovirales. It is the type of RNA virus. The viruses range from $60 \mathrm{~nm}$ to $140 \mathrm{~nm}$ in diameter. It has spurred on the surface which looks like a crown in an electron microscope. That's why named as coronavirus. Before COVID-19 pandemic, there were 6 coronaviruses which caused the infection to humans: 229E, OC43, NL63, HKU1, SARS-CoV, and MERS$\mathrm{CoV}$. Coronaviruses cause diseases in their host species ${ }^{1}$; the one who is infecting humans through interspecies transmission has become a threat to worldwide health. Severe coronavirus pandemics have occurred previously: severe acute respiratory syndrome (SARS) in $2003^{2}$ and the Middle East respiratory syndrome (MERS) in $2012^{3}$. Both these viruses have also believed to be originated from bats.

\section{Epidemiology}

Severe acute respiratory syndrome coronavirus 2 (SARSCoV-2) has caused several cases of severe pneumonia. It started in Wuhan, in China ${ }^{4}$. SARS-CoV-2 causes disease which mainly affects major organs like lung, heart, and kidney ${ }^{5}$. Globally confirmed cases as on 6/5/2020 are 3820703 with 265094 deaths as per the WHO website. Novel Coronavirus or Covid-19 cases in India are well over 50000. Ac- cording to the latest figures from the Ministry of Health, 53025 persons have been infected by the new virus as of May 6, of which. 15331 persons have been cured and discharged. Deaths from it in India are 1785 as on $6^{\text {th }}$ May 2020.

It's been formally labelled as COVID 19 (coronavirus disease 2019) by World Health Organization (WHO) on February 11, 2020. Patients usually report epidemiological exposure. Respiratory droplets are the main source of transmission ${ }^{6-8}$. Infections have been reported in mother as well as a neonate. Though there's no evidence of vertical transmission as well as through breastfeeding, as in the same study by Hauping $\mathrm{Zu}$ et al. all the neonatal pharyngeal swabs were negative for COVID-19 ${ }^{9}$. Average incubation period is 3 to 7 days, while shortest being 1 day and longest 14 days. ${ }^{6-9}$

\section{Clinical manifestations}

Children are mostly asymptomatic. Some may have symptoms of a common cold like fever, dry cough, with runny nose ${ }^{10}$. Very few patients have gastrointestinal tract symptoms, diarrhoea being most common of them. Most children are mildly infected, and the prognosis is rather good. Adult studies have concluded that severe cases present with breathing problem 6 days after initial symptoms ${ }^{6}$. These cases can land up in ARDS, septic shock and coagulopathy. Even myo-

\section{Corresponding Author:}

Sham Balkisanji Lohiya, Associate Professor, Department of Pediatrics, J.N.M.C. Sawangi (D.M.I.M.S.), Sawangi, Wardha, Maharashtra, India; Phone: 8098842537; Email: sham.lohiya19@gmail.com

ISSN: 2231-2196 (Print)

Received: 22.05.2020
ISSN: $0975-5241$ (Online)

Revised: 13.07 .2020
Accepted: 25.08.2020
Published: 08.09.2020 
carditis has been reported. In a retrospective study by Dong et al. about the severity of COVID-19 in children $(n=2143)$, it is been reported that infants were high risk for becoming severely ill among pediatric age group . $10.6 \%$ of all infant cases were categorized as severe. Severely ill were having pneumonia as a most common manifestation $(8.7 \%$ of infant cases). Critically ill children were defined as ARDS requiring mechanical ventilation, which was $1.8 \%$ of infant cases. The median age of children was 7 years (interquartile range: 2-13), and male sex was the majority, 1213 cases (56.6\%). Over $90 \%$ of all patients were not severely ill. Between 1 to 5 years of age $7.3 \%$ became severely ill and $4.2 \%$ for those aged 6 to 15 years. Age group considered for data was below18 years old (7)

COVID-19 rarely presents in infants and newborns. In a study, 9 infants labelled as COVID-19 positive are reported ${ }^{11}$. This is retrospective data. All cases were suspected of epidemiological exposure. Only four infants had a fever out of 9. Two babies had upper respiratory tract symptoms. For 2 babies they didn't get information on symptoms. None of the infants became severely ill. This is contradicting to results by Dong et al. as mentioned above. Because infants younger than 1 year cannot wear masks, their caretakers have to take special precautions. Caretakers should wear masks, wash hands before close contact with infants, and sterilize the infants' toys and tableware regularly. Cases of neonatal infection with SARS-CoV-2 have been reported in China. But none of them acquired the infection through vertical transmission ${ }^{11}$. Newborns may acquire an infection while nursing from infected mothers.

The diagnosis of COVID-19 in the neonate should be suspected if: (a) symptoms like hypothermia or fever, decreased activity, poor feeding, or tachypnea or distress, (b) chest radiographs abnormalities which may include unilateral or bilateral ground-glass opacities, (c) history of exposure to a patient of COVID. All possible cases should be admitted to NICU. There is no recommendation of antiviral drugs for COVID-19 in the neonate. Antibiotics are only applicable if bacterial co-infection is suspected or proven. If newborns present with respiratory distress, it should be managed as other respiratory illnesses are being managed in NICU. Ventilation and nitric oxide inhalation should be considered. The surfactant may be required. In severely ill newborns, parenteral steroids or IVIG may be considered, though efficacy is questionable. Renal replacement therapy and ECMO may also be required. ${ }^{12}$

\section{Bigger concern - If children can act as effec- tive transmitters of the virus}

In China, the reproductive number for COVID-19 estimated is $2^{13}$. Data from China has concluded that kids of schoolgoing age $(<10$ years $)$ measures for $1 \%$ cases of SARS CoV-2 ${ }^{14}$. They are significantly not getting affected. This is in contrast to other viral infections as young children is considered as a risk group for severe illness after getting infected with viruses such as RSV and flu virus. Developing an immune system is thought to be responsible for increased severity of illness by viruses in this age group ${ }^{15}$. Therefore, the absence of pediatric patients in the current pandemic has baffled clinician. Are we missing them?

In a report of 36 pediatric patients having COVID-19 infection, CT chest was done for all children. Ten (28\%) patients were asymptomatic. None of them had severe disease. The most common clinical features were pneumonia symptoms in $53 \%$ case. Next common symptoms were fever and dry cough Treatment for them consisted of aerosolised interferon alfa $(100 \%)$, lopinavir-ritonavir syrup two times a day for 14 days in fourteen (39\%). Oxygen was required by only $17 \%$ of cases. They were sent home after two negative SARSCoV-2 PCR reports. ${ }^{16}$

However, it is not clear which children should receive antiviral or immunomodulatory treatment, because of the high number of asymptomatic infected contacts. This study might suggest that children for some reasons have milder disease. There is a tissue called inducible bronchus-associated lymphoid tissue (BALT). Possibly, lung infiltrates in pediatric SARS-CoV-2 infection act as inducible bronchus-associated lymphoid tissue (BALT) structure development after respiratory insult. Bienenstock originally described BALT as a novel mucosal lymphoid tissue underlying a dome epithelium along the large airways ${ }^{17}$. Other proposed theory is higher angiotensin-converting enzyme (ACE) activity. In children of 4 to 13 years of age, serum ACE progressively increases. After 13, serum ACE level gradually falls. High-ACE activity is also documented in newborns. It may be because of the fast development of lung capillaries after parturition and capillary endothelial cells are principal sources of circulating $\mathrm{ACE}^{18}$. It can be postulated that the effect of COVID-19 on ACE2 may be protective in children.

Kids frequently do not have a serious disease, making them undiagnosed and potential virus transmitter.

\section{Definitions of the severity of COVID-19 in pedi- atric patients ${ }^{7}$}

1. Asymptomatic infection: COVID-19 PCR test is positive, but the patient is completely asymptomatic with normal chest X-ray.

2. Mild: symptoms like fever, tiredness, body ache, cough, throat pain, sneezing. On examination, there may be congestion of pharyngeal wall and no findings on auscultation of the chest. Some can present with only gastrointestinal tract symptoms like diarrhoea and abdominal pain.

3. Moderate: presents with pneumonia. High-grade fever and cough, which is more than that in the mild category. Some may have wheezing, tachypnea and on 
auscultation may have crept which are bilateral. Some cases can be asymptomatic, but their CT thorax shows lung infiltrates.

4. Severe: Early respiratory symptoms such as fever and cough. Gastrointestinal symptoms such as diarrhoea may be associated. After1 week, respiratory distress starts, with hypoxemia. Requires ICU admission.

5. Critical: ARDS with other organ dysfunction like renal failure, myocarditis, coagulopathy. These patients will require ventilation and may require renal replacement therapy and other supportive care.

\section{Investigations}

Diagnosis is done by PCR on upper respiratory tract samples (throat swab/ nasopharyngeal swab) or lower respiratory tract samples (sputum/ endotracheal aspirates and bronchoalveolar lavage).

Send CBC, CRP, RFT, LFT, ECG in patients with severe infection. The total leukocyte count is normal or low with lymphopenia; a lymphocyte count of less than 1000 has been associated with severe illness. CRP and ESR are generally elevated. Cardiac enzymes may be checked if myocardial involvement suspected or shock present. Ferritin and LDH may be checked in severe cases at high risk of developing cytokine storm.

\section{Treatment}

Treatment is mostly supportive. The first step is to isolate the patient to prevent transmission to other patients and healthcare workers. Antibiotics and antivirals such as oseltamivir are of no use and should be deferred in confirmed cases.

\section{Treatment for children with severe acute res- piratory infection in COVID - 19 patients.}

1. Start supplemental oxygen if $\mathrm{SpO} 2<94 \%$ ( target $\mathrm{SpO} 294-98 \%$ ) in children with respiratory distress or shock. Otherwise target $\mathrm{SpO} 2>90 \%$.

2. Nasal prongs or cannula are preferred in children as it may be better tolerated ${ }^{19}$.

3. HFNC may be used preferably over NIV( non-invasive ventilation). It should be used only in patients with hypoxemic respiratory failure in negative pressure room ${ }^{19}$.

4. MDI( metered-dose inhaler) with face mask preferred over nebulisation as the risk of aerosol generation higher with nebulisation.

5. NIV may be used only in selected patients with hypoxemic respiratory failure. Use of conventional ventilator for NIV with non vented oro-nasal masks is preferable over dedicated NIV and use of vented masks. Monitor closely for deterioration and intubate if the patient deteriorates or there is no improvement in 1 hour.

6. In patients with hemodynamic instability, multiorgan failure or altered sensorium invasive ventilation is pre- ferred.

7. In situations where invasive ventilation is not available due to resource limitation bubble, CPAP may be offered for newborn and children with severe hypoxemia.

8. prone ventilation has shown to be beneficial.

9. Use N95 mask with complete PPE including longsleeved gown, goggles or face shield, gloves) for all aerosol-generating procedures.

\section{Aerosol generating procedures \\ - Intubation \\ - Manual bagging before intubation \\ - CPR \\ - Nebulisation \\ - Non-invasive positive pressure ventilation \\ - Open suction \\ - Disconnection from ventilation Tracheostomy}

Ventilation-

- Use low Tidal volume ventilation, $3-6 \mathrm{ml} / \mathrm{kg}$ predicted body weight (PBW) for poor compliance and $5-8 \mathrm{ml} /$ kg PBW with better preserved compliance and maintain target plateau pressure less than 28 .

- Titrate peep for persistent hypoxia. Max PEEP $15 \mathrm{~cm}$ of $\mathrm{H} 20$ for children ( WHO recommendations)

- Offer prone position for $12-16 \mathrm{hrs}$ for patients with moderate to severe ARDS

- Opt for restrictive fluid than liberal fluid therapy.

- Do not use steroids for the patient with pneumonia with no ARDS.

- In patients with severe ARDS low dose methyl perdnisolone 1 - $2 \mathrm{mg} / \mathrm{kg} /$ day for 5 - 7 days

\section{Chemotherapeutics}

Empiric antibiotic therapy should be offered to patients with severe suspected COVID pneumonia and sepsis within 1 hour of admission and appropriate de-escalation and modification may be done depending on culture reports and clinical judgement ${ }^{20}$.

\section{Hydroxy chloroquine}

Two studies are showing promising results of hydroxychloroquine/chloroquine in COVID- 19. Gao et al. have shown that chloroquine worked better as compared to control treatment concerning decreased pneumonia occurrence, better chest imaging findings, early clearance o virus and most importantly decrease in course of disease duration. Data is from over 100 patients $^{21}$. Gautret et al. treated 20 patients with hydroxychloroquine and compared the results with 16 controls in France. They measured the viral load on day 3, 4,5 and 6 of treatment. All categories of patients were taken including asymptomatic. Hydroxychloroquine showed promising results in decreasing viral load. The results on day 3 indicated that $50 \%$ of the hydroxychloroquine-treated 
patients had a viral load reduction with a $\mathrm{p}=0.005$; on day 4 , it showed a $60 \%$ reduction with a $\mathrm{p}=0.04$; on day 5 , a $65 \%$ reduction with a $p=0.006$; and on day $6,70 \%$ of the patients showed viral load reduction with a $\mathrm{p}=0.001$. They have further described the synergistic effect of azithromycin when used along with hydroxychloroquine in decreasing the viral load. The combination treatment showed a $100 \%$ decrease in the viral load with a $\mathrm{p}<0.001$ by day 6 , while hydroxychloroquine alone showed a $70 \%$ decrease $^{22}$.

Adult Dose: 400mg PO BD day 1 followed by 200mg PO BD for 4 days

Pediatric dose ( $<18$ years) : $6.5 \mathrm{mg} / \mathrm{kg} /$ dose (Max 400mg) PO BD day 1 followed by $3.5 \mathrm{mg}$ per $\mathrm{kg}$ PO BD (max 200mg/ dose) for 4 days.

Treatment duration: 5 days. In select patients with extended ventilation or profound immunosuppression, duration may be extended.

Adverse events: Retinopathy, rash, nausea, glucose fluctuations, and diarrhoea. GI symptoms can be mitigated by taking hydroxychloroquine with food.

Contraindications: QT prolongation $>500 \mathrm{msec}$, porphyria, myasthenia gravis, retinal pathology, epilepsy. If baseline QT prolongation is present take frequent ECG.

Avoid taking hydroxyl chloroquine with antacids. Separate administration by at least 4 hours.

Chloroquine Sulphate ( hydroxyl chloroquine (HCQ) is preferred over chloroquine)

Pediatric dose: $10 \mathrm{mg} / \mathrm{kg}$ chloroquine sulphate base stat followed by $5 \mathrm{mg}$ per $\mathrm{kg} 12$ hours later and then $5 \mathrm{mg} / \mathrm{kg} /$ dose BD for 4 more days.

Adult Dose: Chloroquine sulphate base 600mg $(10 \mathrm{mg} / \mathrm{kg})$ stat followed by $300 \mathrm{mg} 12$ hours later and then 300mg BD for 5 days.

\section{Azithromycin}

It is to be given along with HCQ or chloroquine sulphate ${ }^{22,24}$. $10 \mathrm{mg} / \mathrm{kg}$ day 1 (max 500mg) 5mg/kg days $2-5$ (max.250mg)

Zinc inhibits coronavirus RNA polymerase activity and blocks replication of the virus in cell cultures. Zinc $2 \mathrm{mg}$ per $\mathrm{kg}$ per day may be given ${ }^{23}$.

Lopinavir/ ritonavir may be considered in a case to case basis after written consent and medical board concurrence.

Pediatric Dose Lopinavir /ritonavir

14 days to 6 months : $16 \mathrm{mg} / \mathrm{kg} /$ dose ( based on lopinavir component) PO BID

$<15 \mathrm{~kg}$ : $12 \mathrm{mg} / \mathrm{kg} /$ dose PO ( based on lopinavir component)
BID

15-25 kg: 200 mg-50 mg PO BID

26-35 kg: 300 mg-75 mg PO BID

>35 kg: 400 mg-100 mg PO BID

Adult dose

400/100 PO BID

Duration of treatment : 14 days or 7 days after becoming asymptomatic

Adverse events: Hepatotoxicity, pancreatitis, diabetes, QT prolongation, lipid elevations.

- Hydroxychloroquine and lopinavir should not be combined because of a drug interaction.

- Oseltamivir 3mg/kg BID may be given to all children with influenza-like illness till PCR report is available.

\section{Tocilizumab:}

Consider adding to antiviral therapy for patients with rapidly worsening respiratory gas exchange, radiographic infiltrates by imaging (chest $\mathrm{x}$-ray, CT scan, etc.) AND $\mathrm{SpO} 2 \leq 93 \%$ on room air or greater than $6 \mathrm{~L} / \mathrm{min} \mathrm{O} 2$.

It may be offered to patients at high risk for cytokine storm. Criteria for patients at high-risk for developing cytokine storm. Ferritin $>300 \mathrm{ug} / \mathrm{L}$ with doubling within 24 hours, Ferritin $>600 \mathrm{ug} / \mathrm{L}$ at presentation and $\mathrm{LDH}>250$ and Elevated D-dimer $(>1 \mathrm{mg} / \mathrm{L})$

Pediatric Dosing ( $<18 \mathrm{yrs})$ :

$<30 \mathrm{~kg}-12 \mathrm{mg} / \mathrm{kg}$ IV over 60 minutes;

$>30 \mathrm{~kg}-8 \mathrm{mg} / \mathrm{kg}$ IV over 60 minutes ( $\max .800 \mathrm{mg}$ per infusion).

Consider giving an additional 2 dose 8-12 hours later if continued clinical decompensation

Contraindications: Avoid in pregnancy and newborns. Mothers should stop breastfeeding if receiving tocilizumab Monitor liver enzymes in patients receiving tocilizumab.

Serious adverse events: Gastrointestinal perforation, Anemia, Hepatitis, Infusion reaction.

\section{Treatment in concise}

\section{ISOLATION for every case}

Oxygen If $\mathrm{SpO}_{2}<94 \%$

By nasal prongs or non-rebreathing mask

Ventilation If distress persists or With non vented mask patient deteriorates and preferably in negaNIV on Oxygen. tive pressure room

HFNC Preferred over NIV. 0.5- $2 \mathrm{lit} / \mathrm{kg} / \mathrm{min}$. 


\begin{tabular}{|c|c|c|}
\hline ISOLATION & for every case & \\
\hline $\begin{array}{l}\text { Invasive ven- } \\
\text { tilation }\end{array}$ & $\begin{array}{l}\text { Preferable over NIV, } \\
\text { as aerosol generation } \\
\text { risk is not there. }\end{array}$ & $\begin{array}{l}\text { Low tidal volume } \\
\text { strategy. } \\
\text { Adequate PEEP. } \\
\text { Prone ventilation. }\end{array}$ \\
\hline $\begin{array}{l}\text { Hydroxy- } \\
\text { choloroquine } \\
\text { (HCQ) }\end{array}$ & $\begin{array}{l}\text { Given In moderate, } \\
\text { severe and critical } \\
\text { COVID-19 }\end{array}$ & $\begin{array}{l}6.5 \mathrm{mg} / \mathrm{kg} / \text { dose (Max } \\
\text { 40omg) PO BD day } \\
1 \text { followed by } 3.5 \mathrm{mg} \\
\text { per kg PO BD (max } \\
\text { 2oomg/dose) for } 4 \\
\text { days. }\end{array}$ \\
\hline $\begin{array}{l}\text { Chloroquine } \\
\text { Sulphate } \\
\text { ( HCQ is } \\
\text { preferred over } \\
\text { chloroquine) }\end{array}$ & same as HCQ & $\begin{array}{l}10 \mathrm{mg} / \mathrm{kg} \text { chloroquine } \\
\text { sulphate base stat fol- } \\
\text { lowed by } 5 \mathrm{mg} \text { per kg } 12 \\
\text { hours later and then } 5 \\
\mathrm{mg} / \mathrm{kg} / \text { dose BD for } 4 \\
\text { more days. }\end{array}$ \\
\hline Azithromycin & $\begin{array}{l}\text { Along with HCQ or } \\
\text { chloroquine }\end{array}$ & $\begin{array}{l}\text { 10mg } / \mathrm{kg} \text { day } 1 \text { (max } \\
500 \mathrm{mg}) 5 \mathrm{mg} / \mathrm{kg} \text { days } \\
2-5 \text { (max.250mg) }\end{array}$ \\
\hline Zinc & $\begin{array}{l}\text { Can be given in all } \\
\text { cases }\end{array}$ & 2mg per kg per day. \\
\hline Tocilizumab & $\begin{array}{l}\text { Patient requiring } \\
\text { NIV or invasive even- } \\
\text { tilation }\end{array}$ & $\begin{array}{l}<30 \mathrm{~kg}-12 \mathrm{mg} / \mathrm{kg} \mathrm{IV} \\
\text { over } 60 \text { minutes; } \\
>\text { 3okg - 8mg/kg IV } \\
\text { over 6ominutes (max. } \\
\text { 8oomg per infusion). } \\
\text { additional } 2 \text { dose 8-12 } \\
\text { hours apart if contin- } \\
\text { ued clinical decompen- } \\
\text { sation }\end{array}$ \\
\hline
\end{tabular}

\section{Discharge}

If patient better, afebrile for 48 hours and off oxygen with 2 negative samples 24 hours apart.

\section{CONCLUSION}

The SARS-CoV-2, an RNA virus can cause COVID-19. It is extremely infectious; the whole population is susceptible. Respiratory droplets and contact are the main routes of transmission. All age group are susceptible including neonates and infants. Though pediatric age group has been showing the milder degree of disease mostly, they can have severe disease with ARDS which will require PICU care.

\section{Abbreviations}

ACE- Angiotensin-converting enzyme.

ARDS- Acute respiratory distress syndrome.

COVID-19- Coronavirus disease 2019

SARS-CoV- severe acute respiratory syndrome- coronavirus MERS- middle east respiratory syndrome.
CT- Computed tomography.

CBC-Complete blood count

CRP- $C$ reactive protein.

ESR- Erythrocyte sedimentation rate.

LFT- liver function test

KFT- kidney function test.

$\mathrm{SpO} 2$ - oxygen saturation.

HFNC- high flow nasal cannula

NIV- non-invasive ventilation.

MDI- metered-dose inhaler.

\section{ACKNOWLEDGEMENT}

Authors acknowledge the immense help received from the scholars whose articles are cited and included in references to this manuscript. The authors are also grateful to authors/ editors/publishers of all those articles, journals and books from where the literature for this article has been reviewed and discussed.

\section{Conflict of interest: None.}

Financial support: None.

\section{REFERENCES}

1. Shi Z, Hu Z. A review of studies on animal reservoirs of the SARS coronavirus. Virus Res 2008; 133: 7487.

2. Donnelly CA, Ghani AC, Leung GM, et al. Epidemiological determinants of spread of causal agent of severe acute respiratory syndrome in Hong Kong. Lancet 2003; 361: 1761-66.

3. Cauchemez S, Fraser C, Van Kerkhove MD, et al. Middle East respiratory syndrome coronavirus: quantification of the extent of the epidemic, surveillance biases, and transmissibility. Lancet Infect Dis 2014; 14: 50-56.

4. Wu P, Hao X, Lau EHY, et al. Real-time tentative assessment of the epidemiological characteristics of novel coronavirus infections in Wuhan, China, as at 22 January 2020. Euro Surveill 2020; 25: 2000044.

5. Hamming I, Timens W, Bulthuis ML, Lely AT, Navis G, van Goor H. Tissue distribution of ACE2 protein, the functional receptor for SARS coronavirus: the first step in understanding SARS pathogenesis. J Pathol 2004; 203: 631-37.

6. Li Q, Guan X, Wu P, Wang X, Zhou L, Tong Y, et al. Early transmission dynamics in Wuhan, China, of novel coronavirus infected pneumonia. N Engl J Med 2020. https:/www.nejm. org/ doi/10.1056/NEJMoa2001316.

7. Dong Y, Mo X, Hu Y,Qi X, Jiang F, Zongayi J et al. Epidemiological characteristics of 2143 pediatric patients with 2019 coronavirus disease in China. Pediatrics. 2020; DOI: 10.1542/ peds.2020-0702

8. Munster VJ, Koopmans M, van Doremalen N, van Riel D, de Wit E. A novel coronavirus emerging in China d key questions for impact assessment. N Engl J Med 2020;382:692e4.

9. Zhu H, Wang L, Fang C, Peng S, Zhang L, Chang G, et al. Clinical analysis of 10 neonates born to mothers with 2019- nCoV pneumonia. Transl Pediatr 2020;9:51e60. 
10. Guan WJ, Ni ZY, Hu Y, Liang WH, Ou CQ, He JX, et al. Clinical characteristics of 2019 novel coronavirus infection in China. MedRxiv 2020. https://doi.org/10.1101/2020.02.06.20020974.

11. Wei M, Yuan J, Liu Y, Fu T, Yu X, Zhang ZJ. Novel coronavirus infection in hospitalized infants under 1 year of age in China. JAMA 2020. https://doi.org/10.1001/jama.2020.2131.

12. Wang J, Qi H, Bao L, Li F, Shi Y. A contingency plan for the management of the 2019 novel coronavirus outbreak in neonatal intensive care units. Lancet Child Adolesc Health 2020. https:// doi.org/10.1016/S2352-4642(20)30040-7.

13. Zhao S, Lin Q, Ran J, et al. The basic reproduction number of novel coronavirus (2019-nCoV) estimation based on exponential growth in the early outbreak in China from 2019 to 2020: a reply to Dhungana. Int J Infect Dis 2020; published online Feb 20. DOI:10.1016/j.ijid.2020.02.025.

14. Wu Z, McGoogan JM. Characteristics of and important lessons from the coronavirus disease 2019 (COVID-19) outbreak in China: summary of a report of 72314 cases from the Chinese Center for Disease Control and Prevention. JAMA 2020; published online Feb 24. DOI:10.1001/jama.2020.2648.

15. Hong L, Luo Y. Respiratory viral infections in infants: causes, clinical symptoms, virology, and immunology. Clin Microbiol Rev 2010; 23: 74-98.

16. Qiu H, Wu J, Liang H, Yunling L, Song Q, Chen D. Clinical and epidemiological features of 36 children with coronavirus disease 2019 (COVID-19) in Zhejiang, China: an observational cohort study. Lancet Infect Dis 2020; published online March 25.https://doi.org/10.1016/S1473-3099(20)30198-5.

17. Rangel-Moreno J, Hartson L, Navarro C, Gaxiola M, Selman M, Randall TD. Inducible bronchus-associated lymphoid tissue (iBALT) in patients with pulmonary complications of rheumatoid arthritis. J Clin Invest 2006;116: 3183-94
18. Beneteau-Burnat, B., Baudin, B., Morgant, G., Baumann, F. C. \& Giboudeau, J. Serum angiotensin-converting enzyme in healthy and sarcoidotic children: comparison with the reference interval for adults. Clin. Chem. 36, 344-346 (1990).

19. WHO interim guidance 13 March 2020. Clinical management of severe acute respiratory infection (SARI) when COVID - 19 disease is suspected.

20. W Alhazzani, MH Moller, YM Arabi, MN Gong et al. Surviving sepsis campaign: guidelines on the management of critically ill adults with coronavirus disease 2019; Intensive care medicine, European society of intensive care medicine and the society of critical care medicine 2020.

21. Jianjun Gao, Zhenxue Tian, Xu Yang. Breakthrough: Chloroquine phosphate has shown apparent efficacy in the treatment of COVID-19 associated pneumonia in clinical studies. BioScience Trends 2020;14(1):72-3. DOI: 10.5582/bst.2020.01047.

22. Philippe Gautreta, Jean-Christophe Lagiera, Philippe Parolaa, et al. Hydroxychloroquine and azithromycin as a treatment of COVID-19: results of an open-label non-randomised clinical trial. 2020. https://doi.org/10.1016/j.ijantimicag.2020.105949.

23. Velthuis AJW, van den Worm SHE, Sims AC, Baric RS, Snijder EJ, et al. (2010) Zn2+ Inhibits Coronavirus and Arterivirus RNA Polymerase Activity In Vitro and Zinc Ionophores Block the Replication of These Viruses in Cell Culture. PLOS Pathogens 6(11): e1001176

24. Gautret et al. (2020) Hydroxychloroquine and azithromycin as a treatment of COVID - 19: the result of an open-label non randomised clinical trial. International Journal of Antimicrobial Agents -in press 17 March 2020 -DOI : 10.1016/j.ijantimicag.2020.105949

25. Inpatient guidance for treatment of COVID-19 in adults and children. the university of Michigan. 2020 